\title{
PENGARUH KECERDASAN INTELEKTUAL, KECERDASAN EMOSIONAL, DAN LINGKUNGAN KERJA TERHADAP KINERJA KARYAWAN PT. PLN PERSERO AREA KLATEN
}

\author{
Yeni Sugena Putri \\ Jurusan Manajemen Fakultas Ekonomi Universitas Islam Batik \\ Jalan KH. Agus Salim No. 10, Surakarta, Phone +62271714751
}

\begin{abstract}
This study attempts to analyze 1) to know influence intellect intellectual on performance employees of PT. PLN Klaten area. 2) to know the influence of emotional intelligence on performance employees of PT. PLN Klaten area. 3) to know the influence of the workplace on performance employees of PT. PLN Klaten area. 4) to know influence intellect intellectual, emotional intelligence, and workplace simultaneously on performance employees of PT. PLN Klaten area.

Methods used in research is cuantitative method, with the data collected based on the answer quesioner. In this casethe writer used Likert scale. Populations in this research are employee of PT. PLN Klaten area amounting to 69 people, in this research called the population research. Analysis techniques data in this research using multiple linear regression, $t$ test , $F$ test, the coeffiecient determination.

The analysis shows that the: 1$)$ due to $t_{\text {count }}>t_{\text {table }}(3.230>1,996)$ with standard significant 0,05 so Ho rejected and accepetd $\mathrm{Ha}$, it means intellect intellectual have leverage to performance employees of PT. PLN Klaten area. 2) due to $t_{\text {count }}>t_{\text {table }}(4.167>1,996)$ it means $H o$ rejected and receive $H a$ means intelligence intelectual have leverage to performance employees of PT. PLN Klaten area. 3) due to $t_{\text {count }}>t_{\text {table }}(2.362>1,996)$, means $H o$ rejected and receive $H a$ means the workplace have leverage to performance employees of PT. PLN Klaten area. 4) the results of the hypothesis simultaneously in this research, it can be locations that the $f_{\text {count }}>f_{\text {table }}(56,176>2,75)$ it means Ho rejected, it means intellect intellectual, emotional intelligence, and workplace simultaneously have leverage to performance employees of PT. PLN Klaten area. 5) results linear regression analysis double $Y=-5.636+0,397 X_{1}+0,501 X_{2}+0,353 X_{3}$ value adjusted $R$ square $=0,725$ shows that the contribution of all the variables independent is worth $72,5 \%$ the rest of $27.5 \%$ influenced by other variables that is not described in this research.
\end{abstract}

Keywords: Intellectual Intelligence, Emotional Intelligence, Environment of Work and Performance 


\section{PENDAHULUAN \\ Latar Belakang}

Kelangsungan hidup dan pertumbuhan dari suatu perusahaan tidak hanya dapat ditentukan dan di nilai dari keberhasilan dalam pengelolaan keuangan, pemasaran serta produknya, tetapi juga dapat ditentukan dari pengelolaan sumber daya manusia. Agar dapat bersaing dalam persaingan bisnis, Sumber daya terpenting bagi suatu perusahaan atau organisasi adalah sumber daya manusia yaitu orang yang telah memberikan tenaga, bakat, kreativitas dan usaha mereka pada organisasi (Handoko, 2001 : 133).

Kita bisa menggunakan kecerdasan intelektual yang menonjolkan kemampuan logika berpikir untuk menemukan fakta obyektif, akurat, dan untuk memprediksi resiko, melihat konsekuensi dari setiap keputusan yang ada.Banyak penelitian yang membahas dan menjawab persoalan mengenai kecerdasan emosi tersebut di dalam lingkungan organisasi, Goleman (2002:56) mengatakan bahwa kecerdasan emosional adalah kemampuan lebih yang dimilliki individu dalam memotivasi diri, ketahanan dalam menghadapi kegagalan, mengendalikan emosi dan menunda kepuasan, serta mengatur keadaan jiwa. Dengan kecerdasan emosional, individu dapat menempatkan emosinya pada porsi yang tepat, memilah kepuasan dan mengatur suasana hati. Individu yanng memiliki kecerdasan emosional yang tinggi dapat menanggulangi emosi mereka sendiri dengan baik, dan memperhatikan kondisi emosinya, serta merespon dengan benar emosinya untuk orang lain. lingkungan kerja harus baik dan kondusif karena lingkungan kerja yang baik dan kondusif menjadikan karyawan merasa betah berada di ruangan dan merasa senang serta bersemangat untuk melaksanakan tugas-tugasnya. Kinerja karyawan mengacu pada prestasi seseorang yang diukur berdasarkan standar atau kriteria yang ditetapkan oleh perusahaan/organisasi.Pada umumnya perusahaan yang tidak mampu menghadapi persaingan memiliki kinerja yang berkualitas rendah. Mampu membawa organisasi perusahaan dalam memasuki lingkungan bisnis.

PT. PLN (Persero) Area Klaten yang berlokasi di Kabupaten Klaten merupakan suatu instansi pemerintah atau badan usaha yang bergerak di bidang penyediaan listrik yang melaksanakan dan menunjang kebijaksanaan pemerintah di bidang ekonomi, pembangunan nasional, serta meningkatkan taraf hidup pada masyarakat yang adil dan makmur secara material dan spiritual pada umumnya dan meningkatkan taraf hidup orang banyak. Namun tugas ini tidaklah ringan, karena seorang karyawan akan di katakan baik apabila karyawan tersebut memiliki keahlian (skill) yang tinggi.

Adapun masalah dari penelitian ini meliputi pertanyaan Apakah kecerdasan intelektual, kecerdasan emosional, dan lingkungan kerja secara simultan berpengaruh terhadap kinerja karyawan PT. PLN (Persero) Area Klaten, Apakah kecerdasan intelektual berpengaruh terhadap kinerja karyawan PT. PLN (Persero) Area Klaten, Apakah kecerdasan emosional berpengaruh terhadap kinerja karyawan PT. PLN (Persero) Area Klaten, Apakah lingkungan kerja berpengaruh terhadap kinerja karyawan PT. PLN (Persero) Area Klaten.

Tujuan yang ingin dicapai dalam penelitian ini adalah yang pertama untuk mengetahui atau menganalisa pengaruh kecerdasan intelektual, kecerdasan emosional, dan lingkungan kerja secara simultan terhadap kinerja karyawan PT. PLN (Persero) Area Klaten. Kedua, untuk 
mengetahui atau menganalisa pengaruh kecerdasan intelektual terhadap kinerja karyawan PT. PLN (Persero) Area Klaten. Ketiga, untuk mengetahui atau menganalisa pengaruh kecerdasan emosional terhadap kinerja karyawan PT. PLN (Persero) Area Klaten. Keempat, untuk mengetahui atau menganalisa pengaruh lingkungan kerja terhadap kinerja karyawan PT. PLN (Persero) Area Klaten.

\section{Tinjauan Pustaka}

Kinerja Karyawan

1. Pengertian Kinerja

Menurut Anwar Prabu

Mangkunegara (2006 : 67) bahwa kinerja (prestasi kerja) adalah hasil kerja secara kualitas dan kuantitas yang dicapai oleh seorang pegawai dalam melaksanakan tugasnya sesuai dengan tanggung jawab yang diberikan kepadanya. Kinerja menurut Robert L. Mathis dan John H. Jackson (2006 : 378) adalah apa yang dilakukan atau tidak dilakukan oleh karyawan.

2. Kriteria kinerja

Bernadin (1993 : 75) menjelaskan bahwa kinerja sesorang dapat diukur berdasarkan 6 kriteria yang dihasilkan dari pekerjaan yang bersangkutan. Keenam kriteria tersebut adalah :

Kualitas. Kualitas merupakan tingkatan dimana hasil akhir yang dicapai mendekati sempurna dalam arti memenuhi tujuan yang diharapkan oleh perusahaan.

Kuantitas. Kuantitas adalah jumlah yang dihasilkan yang dinyatakan dalam istilah sejumlah unit kerja ataupun merupakan jumlah siklus aktivitas yang dihasilkan.

Ketepatan waktu. Tingkat aktivitas di selesaikannya pekerjaan tersebut pada waktu awal yang diinginkan.
Efektifitas. Efektifitas merupakan tingkat pengetahuan sumber daya organisasi dimana dengan maksud menaikkan keuntungan.

Kemandirian. Karyawan dapat melakukan fungsi kerjanya tanpa meminta bantuan dari orang lain.

Komitmen. Komitmen berarti bahwa karyawan mempunyai tanggung jawab penuh terhadap pekerjaannya.

Kecerdasan Intelektual (Intelligence Quotient)

1. Pengertian Kecerdasan Intelektual

Kecerdasan Intelektual mampu bekerja mengukur kecepatan, mengukur hal-hal baru, menyimpan dan mengingat kembali informasi objektif serta berperan aktif dalam menghitung angka-angka dan lainlain.Kita bisa menggunakan kecerdasan intelektual yang menonjolkan kemampuan logika berpikir untuk menemukan fakta obyektif, akurat, dan untuk memprediksi resiko, melihat konsekuensi dari setiap keputusan yang ada. Menurut Sunar (2010 : 160), Kecerdasan Intelektual (IQ) dapat didefenisikan sebagai kemampuan untuk bekerja secara abstrak, baik menggunakan ide-ide, simbol, hubungan logis, maupun konsep-konsep teoritis. Kemampuan untuk mengenali dan belajar serta menggunakan abstraksi tersebut. Kemampuan untuk menyelesaikan masalah termasuk masalah yang baru.

2. Kemampuan Kecerdasan Intelektual Menurut Muzert (dalam Yuliana, 2006 : 27), identifikasi kemampuan intelektual tertuang dalam sikap inteligensi (intelligent behavior) yang meliputi mengenalkan soal pengetahuan dan informasi ke pengertian yang lebih luas, ingatan, aplikasi akan tepatnya belajar dari 
situasi yang berlangsung, kecepatan memberikan jawaban dalam penyelesaian dankemampuan memecahkan masalah, dan keseluruhan tindakan menempatkan segalanya dengan seimbang dan efisien.

Kecerdasan Emosional

1. Kecerdasan Emosional menurut para ahli

Menurut Agustian (2003:61), kecerdasan emosional adalah serangkaian kecakapan untuk melapangkan jalan di dunia yang penuh liku-liku permasalahan sosial. Ari Ginanjar (2003:62), juga menyimpulkan bahwa Kecerdasan emosional adalah sebuahkemampuan untuk "mendengarkan" bisikan emosi, dan menjadikannya sebagai sumber informasi maha penting untuk memahami diri sendiri dan orang lain demi mencapai sebuah tujuan. Sikap kreatif, konsisten, berani mengambil keputusan dan memiliki tekad yang tangguh adalah sikap yang dipelajari dalam kecerdasan emosional.

2. Pengukuran Kecerdasan Emosional Kecerdasan Emosi dapat diukur dari beberapa aspek-aspek yang ada. Goleman (2001 : 42-43) mengemukakan lima kecakapan dasar dalam kecerdasan Emosi, yaitu:

Self awareness. Merupakan kemampuan sesorang untuk mengetahui perasaan dalam dirinya dan efeknya serta menggunakannya untuk membuat keputusan bagi diri sendiri, memiliki tolak ukur yang realistis, atau kemampuan diri dan mempunyai kepercayaan diri yang kuat lalu mengkaitkannya dengan sumber penyebabnya.

Self management. Merupakan kemampuan menangani emosinya sendiri, mengekspresikan serta mengendalikan emosi, memiliki kepekaan terhadap kata hati, untuk digunakan dalam hubungan dan tindakan sehari-hari.

Motivation. Motivasi adalah kemampuan menggunakan hasrat untuk setiap saat membangkitkan semangat dan tenaga untuk mencapai keadaan yang lebih baik serta mampu mengambil inisiatif dan bertindak secara efektif, mampu bertahan menghadapi kegagalan dan frustasi.

Empati (social awareness). Empati merupakan kemampuan merasakan apa yang dirasakan oleh orang lain, mampu memahami perspektif orang lain, dan menimbulkan hubungan saling percaya serta mampu menyelaraskan diri dengan berbagai tipe individu.

Relationship management. Merupakan kemampuan menangani emosi dengan baik ketika berhubungan dengan orang lain dan menciptakan serta mempertahankan hubungan dengan orang lain, bisa mempengaruhi, memimpin, bermusyawarah, menyelesaikan perselisihan dan bekerja sama dalam tim.

Lingkungan Kerja

1. Lingkungan Kerja menurut ahli Menurut Robbins (2003 : 86) lingkungan adalah lembaga-lembaga atau kekuatan-kekuatan diluar yang berpotensi mempengaruhi kinerja organisasi, lingkungan dirumuskan menjadi dua yaitu lingkungan umum dan lingkungan khusus.

Kondisi lingkungan kerja dikatakan baik apabila manusia dapat melaksanakan kegiatan secara optimal, sehat, aman dan nyaman. Penyesuaian lingkungan kerja dapat dilihat dalam jangka waktu kerja yang lama, lingkungan kerja yang 
kurang baik dan sehat dapat menuntut tenaga kerja dan waktu yang lebih banyak terbuang dan tidak mendukung diperolehnya rancangan sistem kerja yang efektif dan efisien. Lingkungan kerja adalah segala sesuatu yang ada di sekitar para pekerja yang dapat mempengaruhi dirinya dalam menjalankan tugastugas yang diembankan (Nitisemito, $2000: 183$ ).

2. Jenis Lingkungan Kerja

Menurut Sedarmayanti (2009 : 21) "secara garis besar, jenis lingkungan kerja terbagi menjadi 2 yakni: 1) lingkungan kerja fisik, dan 2) lingkungan kerja non fisik".

Lingkungan Kerja Fisik. Menurut Sedarmayanti (2009 :22) "lingkungan kerja fisik adalah semua yang terdapat disekitar tempat kerja yang dapat mempengaruhi pegawai baik secara langsung maupun tidak langsung".

Lingkungan Kerja Non Fisik. Menurut Sedarmayanti (2009 :31) menyatakan bahwa lingkungan kerja non fisik adalah semua keadaan yang terjadi yang berkaitan dengan hubungan kerja, baik dengan atasan maupun dengan sesama rekan kerja ataupun hubungan dengan bawahan".

\section{Hipotesa}

Hipotesis adalah dugaan yang sifatnya sementara dan perlu diadakan uji kebenarannya. Dalam penelitian ini hipotesis yang kemukakan adalah sebagai berikut :

1. Diduga kecerdasan intelektual, kecerdasan emosional, dan lingkungan kerja secara simultan mempunyai pengaruh yang positif dan signifikan terhadap kinerja karyawan.

2. Diduga kecerdasan intelektual mempunyai pengaruh yang positif dan signifikan terhadap kinerja karyawan.

3. Diduga kecerdasan emosional mempunyai pengaruh yang positif dan signifikan terhadap kinerja karyawan.

4. Diduga lingkungan kerja mempunyai pengaruh yang positif dan signifikan terhadap kinerja karyawan.

\section{Kerangka Pemikiran}

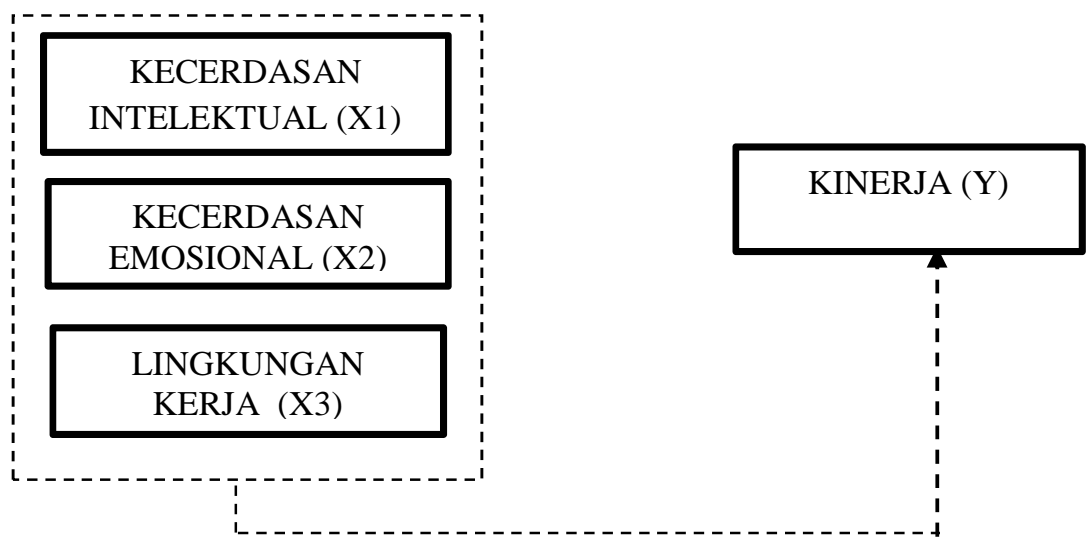




\section{METODE PENELITIAN}

Metode yang di gunakan dalam penelitian ini adalah metode kuantitatif, dengan data yang diperoleh berdasarkan jawaban kuesioner.Dalam hal ini penulis menggunakan skala Likert.Populasi dalam penelitian ini adalah karyawn PT. Pln Persero Area Klaten yang berjumlah 69 orang, dalampenelitian ini di sebut penelitian populasi.Teknik analisis data dalam penelitian ini menggunakan regresi linier berganda, uji t, uji $f$, koefisien determinasi.

\section{METODE ANALISIS DATA Uji Multikolinearitas}

Untuk mengetahui ada atau tidaknya multikolinearitas pada sebuah variabel dapat diketahui dengan nilai Variance Inflaction Factor (VIF) dan nilai Tolerance masing-masing dari variabel bebasnya. Apabila nilai VIF $<10$ dan nilai Tolerance > 0,1 maka dapat dinyatakan tidak ada indikasi multikolinearitas antara variabel bebasnya.

Tabel 1

Hasil Uji Multikolinearitas

\begin{tabular}{ccccc}
\hline No & Variabel & Tolerance & VIF & Keterangan \\
\hline 1. & Kecerdasan Intelektual & .391 & 2.559 & Tidak ada multikolinearitas \\
2. & Kecerdasan Emosional & .374 & 2.672 & Tidak ada multikolinearitas \\
3. & Lingkungan Kerja & .573 & 1.745 & Tidak ada multikolinearitas \\
\hline
\end{tabular}

Sumber : Data Primer, tahun 2016

\section{Uji Heterokedastisitas}

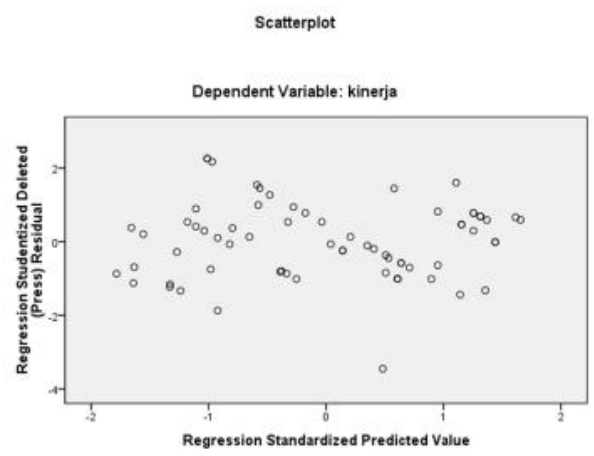

Uji Normalitas

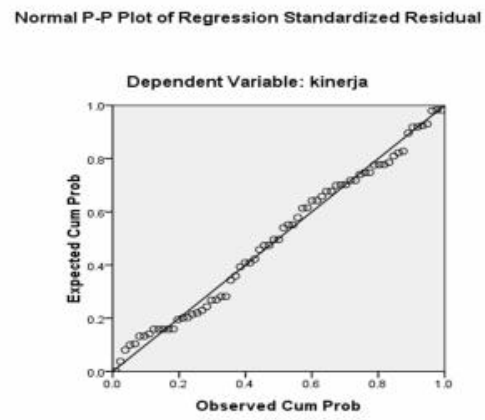




\section{Analisis Regresi Linier Berganda}

Tabel 2

Hasil Estimasi Regresi

\begin{tabular}{lrrrrr}
\hline \multicolumn{1}{c}{ Model } & \multicolumn{1}{c}{$\begin{array}{l}\text { Unstandardized } \\
\text { Coefficients }\end{array}$} & $\begin{array}{l}\text { Standardized } \\
\text { Coefficients }\end{array}$ & $\mathbf{t}$ & Sig. \\
& B & Std. Error & \multicolumn{1}{c}{ Beta } & & \\
\hline (Constant) & -5.636 & 2.252 & & -2.503 & .015 \\
Kecerdasan Intelektual & .397 & .123 & .328 & 3.230 & .002 \\
Kecerdasan Emosional & .501 & .120 & .433 & 4.167 & .000 \\
Lingkungan Kerja & .353 & .149 & .198 & 2.362 & .021 \\
\hline
\end{tabular}

Sumber : data primer diolah, 2016

Berdasarkan tabel di atas dapat dibentuk suatu persamaan regresi dengan model taksiran sebagai berikut :

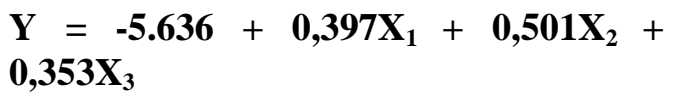

Uji F

Tabel 3

Hasil analisis regresi secara simultan ANNOVA $^{\mathrm{a}}$

\begin{tabular}{llrrrrr}
\hline Model & $\begin{array}{l}\text { Sum } \\
\text { Squares }\end{array}$ & of & Df & $\begin{array}{c}\text { Mean } \\
\text { Square }\end{array}$ & F & Sig \\
\hline 1 Regression & 825.877 & 3 & 275.292 & 60.838 & $.000^{\mathrm{a}}$ \\
Residual & 294.123 & 65 & 4.525 & & \\
$\quad$ Total & 1120.000 & 68 & & & \\
\hline
\end{tabular}

a. Dependent Variable: Kinerja

b. Predictors: (Constant), Kecerdasan Intelektual, Kecerdasan Emosional, Lingkungan Kerja Sumber : Data Primer, tahun 2016

Adapun langkah - langkah pengujian adalah sebagai berikut :

1. Menentukan Ho dan Ha

Ho: $\beta_{1}=\beta_{2}=\beta_{3}=\mathbf{0}$, Berarti tidak ada pengaruh kecerdasan intelektual (X1), kecerdasan emosional (X2), dan lingkungan kerja (X3) terhadap kinerja karyawan (Y).

Ha: $\beta_{1} \neq \beta_{2} \neq \beta_{3} \neq 0$, Berarti ada pengaruh antara kecerdasan intelektual $\left(\mathrm{X}_{1}\right), \quad$ kecerdasan emosional $\left(\mathrm{X}_{2}\right)$, lingkungan kerja $\left(\mathrm{X}_{3}\right)$, terhadap kinerja karyawan $(\mathrm{Y})$.

2. Taraf signifikan yang digunakan adalah $=0,05$

Nilai $\mathrm{F}_{\text {tabel }}=(\mathrm{k}-1 ; \mathrm{n}-\mathrm{k})=0,05(4-1$; $69-4)=0,05(3 ; 65)$

$\mathrm{F}_{\text {tabel }}=2,75$

$$
=56,176>2,75
$$

3. Kriteria Pengujian

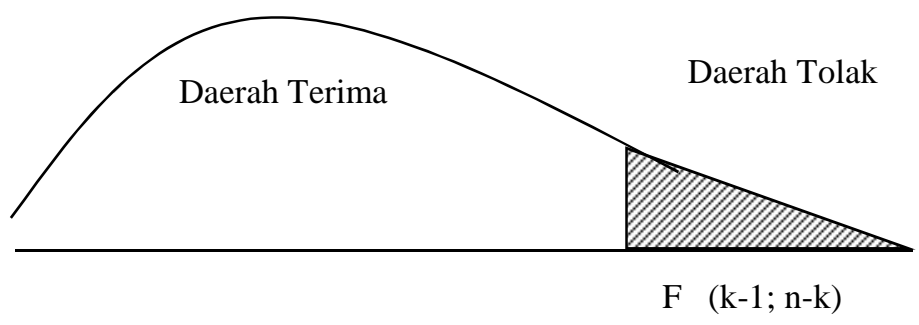


Ho diterima apabila $\mathrm{F}_{\text {hitung }} \leq \mathrm{F}_{\text {tabel }}$ Ho ditolak apabila $F_{\text {hitung }}>F_{\text {tabel }}$

4. Nilai F hitung

Berdasarkan hasil olah data melalui program SPSS hasil $F_{\text {hitung }}$ sebesar 56,176

5. Keputusan

Dari hasil analisis uji $\mathrm{F}$ dengan program SPSS, diperoleh hasil $\mathrm{F}_{\text {hitung }}$ sebesar 56, 176 sedangkan nilai $\mathrm{F}_{\text {tabel }}$ sebesar 2,75. Jadi, $F_{\text {hitung }}>\quad F_{\text {tabel }}$, sehingga Ho ditolak berarti ada pengaruh secara simultan antara variabel kecerdasan intelektual $\left(\mathrm{X}_{1}\right)$, kecerdasan emosional $\left(\mathrm{X}_{2}\right)$, dan lingkungan kerja $\left(\mathrm{X}_{3}\right)$ terhadap kinerja pegawai (Y).

\section{Uji t}

Tabel 4

Hasil Uji t secara Parsial

\begin{tabular}{lcc}
\hline \multicolumn{1}{c}{ Variabel Bebas } & $\mathbf{t}_{\text {hitung }}$ & $\mathbf{t}_{\text {tabel }}$ \\
\hline Kecerdasan Intelektual & 3.230 & 1,996 \\
Kecerdasan Emosional & 4.167 & 1,996 \\
Lingkungan Kerja & 2.362 & 1,996 \\
\hline
\end{tabular}

Sumber : Data Primer, tahun 2016

Analisis Koefisien Determinasi $\left(\mathbf{R}^{2}\right)$

Tabel 5

Koefisien Determinasi Model Summary ${ }^{b}$

\begin{tabular}{|c|c|c|c|c|}
\hline Model & $\mathbf{R}$ & R Square & $\begin{array}{l}\text { Adjusted R } \\
\text { Square }\end{array}$ & $\begin{array}{l}\text { Std. Error of the } \\
\text { Estimate }\end{array}$ \\
\hline 1 & $.859^{\mathrm{a}}$ & .737 & .725 & 2.127 \\
\hline
\end{tabular}

Sumber dari : SPSS

Hasil dari perhitungan regresi dapat diketahui bahwa koefisien determinasi $\left(\mathrm{R}^{2}\right)$ yang diperoleh sebesar 0,725 . Hal ini berarti $72,5 \%$ variasi variabel kinerja karyawan dapat dijelaskan oleh variabel kecerdasan intelektual, kecerdasan emosional dan lingkungan kerja sedangkan sisanya sebesar $27,5 \%$ diterangkan oleh variabel lain yang tidak diajukan dalam penelitian ini.

\section{PEMBAHASAN}

1. Pengaruh kecerdasan intelektual, kecerdasan emosional, dan lingkungan kerja terhadap kinerja secara bersama-sama dengan uji $\mathrm{F}$ yaitu hasil yang diperoleh $F_{\text {hitung }}$ sebesar 56,176 sedangkan nilai $\mathrm{F}_{\text {tabel }}$ sebesar 2,75. Jadi, $F_{\text {hitung }}>\quad F_{\text {tabel }}$, sehingga Ho ditolak berarti ada pengaruh secara simultan antara variabel kecerdasan intelektual $\left(\mathrm{X}_{1}\right)$, kecerdasan emosional $\left(\mathrm{X}_{2}\right)$, dan lingkungan kerja $\left(\mathrm{X}_{3}\right)$ terhadap kinerja karyawan (Y). Hal ini bisa disimpulkan ketika ketiga variabel tersebut mengalami peningkatan sudah pasti kinerja karyawan juga ikut mengalami peningkatan.

2. Pengaruh kecerdasan intelektual terhadap kinerja dengan uji $t$ yaitu hasil yang diperoleh $t_{\text {hitung }}>$ $\mathrm{t}_{\text {tabel }}(3.230)>(1,996)$ dengan taraf signifikasi 0,05 maka Ho ditolak sehingga ada pengaruh yang signifikan kecerdasan intelektual 
terhadap kinerja karyawan. Jika dilihat dari pola hubungannya, maka pengaruh kecerdasan intelektual terhadap kinerja adalah positif. Artinya semakin baik kecerdasan intelektual, maka kinerja karyawan semakin baik. Baiknya kecerdasan intelektual dapat memberikan pengaruh terhadap kinerja karyawan yang baik.

3. Pengaruh kecerdasan emosional terhadap kinerja dengan uji t yaitu hasil yang diperoleh $t_{\text {hitung }}(4.167)>$ $\mathrm{t}_{\text {tabel }}(1,996)$ dengan taraf signifikasi 0,05 maka Ho ditolak sehingga ada pengaruh yang signifikan kecerdasan emosional terhadap kinerja karyawan. Jika dilihat dari pola hubungannya, maka kecerdasan emosional memberikan pengaruh positif terhadap kinerja.Artinya semakin baik kecerdasan emosional, maka kinerja semakin baik.Baiknya kecerdasan emosional dapat memberikan pengaruh terhadap kinerja karyawan.

4. Pengaruh lingkungan kerja terhadap kinerja dengan uji t yaitu hasil yang diperoleh $t_{\text {hitung }}(2.362)>t_{\text {tabel }}(1,996)$ dengan taraf signifikasi 0,05 maka Ho ditolak sehingga ada pengaruh yang signifikan lingkungan kerja terhadap kinerja karyawan. Jika dilihat dari pola hubungannya, maka lingkungan kerja memberikan pengaruh positif terhadap kinerja. Artinya semakin baik lingkungan kerja, maka kinerja semakin baik. Lingkungan kerja dapat memberikan pengaruh terhadap kinerja karyawan.

5. Pengaruh kecerdasan intelektual, kecerdasan emosional dan lingkungan kerja terhadap kinerja karyawan dengan menggunakan koefisien determinasi $\left(\mathrm{R}^{2}\right)$ hasil yang diperoleh sebesar 0,725. Hal ini berarti $72,5 \%$ variasi variabel kinerja karyawan dapat dijelaskan oleh variabel kecerdasan intelektual, kecerdasan emosional dan lingkungan kerja, sedangkan sisanya sebesar $27,5 \%$ diterangkan oleh variabel lain yang tidak diajukan dalam penelitian ini atau di luar variabel kecerdasan intelektual, kecerdasan emosional, dan lingkungan kerja.

6. Berdasarkan hasil output SPSS 16 for Windows diketahui $\mathrm{t}_{\text {hitung }}$ variabel yang paling dominan berpengaruh terhadap kinerja karyawan yaitu variabel kecerdasan intelektual $\left(t_{\text {hitung }}\right.$ $=3.230$ ) dari pada variabel kecerdasan emosional $\left(t_{\text {hitung }}=4.167\right.$ ), dan variabel lingkungan kerja $\left(t_{\text {hitung }}=2.362\right)$, sehingga hipotesa yang diajukan yaitu kepemimpinan transaksional mempunyai pengaruh yang dominan terhadap kinerja pegawai, terbukti atau dapat diterima.

\section{PENUTUP}

\section{Kesimpulan}

Dari hasil penelitian dan analisa dapat di tarik kesimpulan sebagai berikut :

1. Kecerdasan Intelektual $\left(\mathrm{X}_{1}\right)$, Kecerdasan Emosional $\left(\mathrm{X}_{2}\right)$, dan Lingkungan Kerja $\left(\mathrm{X}_{3}\right)$ secara simultan berpengaruh positif dan signifikan terhadap Kinerja Karyawan (Y). Hal ini bisa disimpulkan bahwa ketiga variabel tersebut secara simultan mengalami peningkatan, sehingga kinerja karyawan juga ikut mengalami peningkatan.

2. Kecerdasan Intelektual $\left(\mathrm{X}_{1}\right)$ secara parsial berpengaruh positif dan signifikan terhadapKinerja karyawan (Y). Jadi, semakin tinggi kecerdasan intelektual seorang karyawan dalam menjalankan pekerjaan, maka 
semakin tinggi pula kinerja yang dihasilkan oleh karyawan tersebut.

3. Kecerdasan Emosional $\left(\mathrm{X}_{2}\right)$ secara parsial berpengaruh positif dan signifikan terhadap Kinerja karyawan (Y). Sehingga semakin tinggi kecerdasan emosional seorang karyawan dalam menjalankan pekerjaan maka semakin tinggi pula kinerja yang dihasilkan oleh karyawan tersebut

4. Lingkungan Kerja $\left(\mathrm{X}_{3}\right)$, secara parsial berpengaruh positif dan signifikan terhadap Kinerja karyawan(Y). Sehingga semakin nyaman dan kondusiflingkungan kerja, maka kinerja yang di jalankan olehseorang karyawan semakin meningkat.

\section{Daftar Pustaka}

Agustian, Ari Ginanjar. 2003. ESQ Power:Sebuah Inner Journey Melalui AlIhsan. Jakarta: Penerbit Arga.

Benardin, Jhon H and Joyce E. A. Russel, 1993. Human Resources Management and ExperientalApproach, Singapore: Mc Graw mill.

Goleman, D. 2002. Emotional Intelligence- Kecerdasan Emosional. Jakarta: PT Gramedia Pustaka Utama.

Handoko, T.H. 2001.Manajemen Personalia dan Sumber Daya Manusia.Yogyakarta: BPFE Press.

Mangkunegara, Anwar P. 2006. Evaluasi Kinerja Sumber Daya Manusia. Bandung: PT. Refika Aditama.

Mathis, Robert L, Jackson, John H (2002). Manajemen Sumber Daya Manusia. Jakarta: Salemba Empat.

Nitisemito, Alex S. 2000. Manajemen Personalia: Manajemen Sumber Daya Manusia, Ed. 3. Jakarta: Ghalia Indonesia

Robbins, Stephen, P. 2003. Prinsip-Prinsip Perilaku Organisasi. Jakarta: Erlangga.

Sedarmayanti.2009. Tata Kerja dan Produktivitas Kerja. Bandung: Mandar Maju.

www.pln.co.id 